\title{
Marcas territoriales y desarrollo local en la Cataluña interior. Estudio de caso: Territoris serens (el Lluçanès)
}

\author{
Jordi de San Eugenio Vela \\ Universitat de Vic. Departament de Comunicació \\ jordi.saneugenio@uvic.cat \\ Montse Barniol Carcasona \\ Universitat de Girona. Departament de Geografia \\ montserrat.barniol@udg.edu
}

\section{Resumen}

La denominada «reestructuración rural» pasa ineludiblemente por la transformación de la economía de sector primario que tradicionalmente ha sustentado al campo. En los últimos tiempos, se experimenta una clara tercerización de la economía rural, en muy buena medida capitalizada por la industria turística. En este sentido, surge la necesidad de repensar la ruralidad, de construirla socialmente a partir de la proyección de imaginarios comunicados interna y externamente mediante la ayuda de marcas territoriales. El presente trabajo tiene como objetivo prioritario explorar de qué forma la marca espacial Territoris serens permite la creación de una imagen competitiva para la agrupación territorial del Lluçanès, por medio de la difusión de relatos asociados a diversos valores intangibles encabezados por la serenidad, el paisaje y, por ende, la identidad territorial. La revisión de la literatura referida a marcas de territorio, el análisis de la producción documental vinculada a Territoris serens y la organización de un grupo focal de discusión permitirá dirimir el proceso de transformación de territorios en marcas, en aras de conseguir, en nombre de la competitividad, un renovado y posmoderno "sentido de lugar».

Palabras clave: desarrollo local; marca territorial; ruralidad; geografía; Lluçanès.

Resum. Marques territorials i desenvolupament local a la Catalunya interior. Estudi de cas: "Territoris serens» (el Lluçanès)

L'anomenada «reestructuració rural» passa ineludiblement per la transformació de l'economia de sector primari que tradicionalment ha sustentat el camp. En els últims temps, s'experimenta una clara terciarització de l'economia rural, en molt bona mesura capitalitzada per la indústria turística. En aquest sentit, sorgeix la necessitat de repensar la ruralitat, de construir-la socialment a partir de la projecció d'imaginaris comunicats 
interna i externament mitjançant l'ajuda de marques territorials. Aquest treball té com a objectiu prioritari explorar de quina manera la marca espacial Territoris serens permet crear una imatge competitiva per a l'agrupació territorial del Lluçanès, per mitjà de la difusió de relats associats a diversos valors intangibles encapçalats per la serenitat, el paisatge i, per tant, també per la identitat territorial. La revisió de la literatura referida a marques de territori, l'anàlisi de la producció documental vinculada a Territoris serens i l'organització d'un grup focal de discussió permetrà dirimir el procés de transformació de territoris en marques, per tal d'aconseguir, en nom de la competitivitat, un renovat i postmodern «sentit de lloc».

Paraules clau: desenvolupament local; marca territorial; ruralitat; geografia; Lluçanès.

Résumé. Marques territoriales et développement local dans la Catalogne intérieure. Une étude de cas: "Territoris serens» (le Lluçanès)

La dénommée «restructuration rurale» passe inéluctablement par la transformation de l'économie du secteur agricole qui a traditionnellement soutenu le champ. Dans les derniers temps, on expérimente une nette tendance de l'économie rurale vers les services, commandée principalement par l'industrie touristique. Dans ce sens, il est devenu nécessaire de repenser la ruralité, de la construire socialement à partir de la projection d'imaginaires communiqués interne et extérieurement au moyen de l'aide de marques territoriales. L'objectif prioritaire de cet travail est d'explorer comment la marque spatiale Territoris serens permet la création d'une image compétitive pour le groupe territorial du Lluçanès, au moyen de la diffusion de récits associés à diverses valeurs intangibles dirigées par la sérénité, le paysage et, par conséquent, l'identité territoriale. La révision de la littérature rapportée aux marques de territoire, l'analyse de la production documentaire liée à Territoris serens et l'organisation d'un groupe focal de discussion permettra de dirimer le processus de transformation de territoires dans des marques, avec l'objectif d'obtenir, au nom de la compétitivité, un renouvelé et postmoderne «sens de lieu».

Mots clé: développement local; marque territoriale; ruralité; géographie; Lluçanès.

Abstract. Place brands and local development in inner Catalonia: A case study of the Territoris serens (el Lluçanès)

So-called «rural restructuring» necessarily entails the transformation of the primary sector of the economy, which has been the traditional mainstay of the countryside. In recent years, the rural economy has undergone a clear process of outsourcing, which has to a large extent been capitalized on by the tourism industry. This has led to the need to rethink the concept of rurality and build it socially through the internal and external projection of imageries with the help of place brands. The main aim of this article is to explore how the Territoris serens spatial brand permits the creation of a competitive image for the Lluçanès territorial association through the diffusion of stories associated with several intangible values embodying serenity, the landscape, and hence the territorial identity. The review of the literature on place brands, the analysis of documents related to Territoris serens and the organization of a focus group discussion sheds light on the process to transform territories into brands in order to achieve, with a view to competitiveness, a renewed and postmodern "sense of place».

Keywords: local development; place brand; rurality; geography; Lluçanès. 


\begin{aligned} & \multicolumn{2}{c}{ Sumario } \\ & Introducción Resultados \\ & Metodología Discusión y conclusiones \\ & El marco teórico Agradecimientos \\ & El territorio y el proyecto objeto Referencias bibliográficas \\ & de estudio \end{aligned}

\section{Introducción}

Los espacios rurales afrontan el proceso de globalización mediante la transformación de sus economías. El tradicional sustento que antaño suponía la producción agrícola ha derivado hacia una nueva economía fundamentada en la comercialización del espacio rural (Fløysand y Jakobsen, 2007). Asimismo, surge la necesidad de generar un nuevo discurso espacial que discurre, en parte, a través de la construcción de narrativas, de renovados relatos con capacidad para satisfacer las necesidades de los potenciales consumidores, en su mayor parte turistas. En este contexto, debemos situar el proyecto de desarrollo local Territoris serens, objeto principal de análisis de este artículo. En este sentido, se abordará en primer lugar el análisis de la propuesta de desarrollo local de referencia desplegada recientemente en el Lluçanès. En segundo lugar, interesará determinar en qué forma este mismo proceso de desarrollo local se produce en paralelo a la fijación de una identidad territorial en los niveles interno y externo, vehiculada mediante la proyección de una marca territorial íntimamente asociada al atributo de serenidad. A nivel estructural, el texto distribuye sus contenidos a partir de la definición de un marco teórico suministrado esencialmente por las aportaciones de las marcas territoriales, así como por sus procesos de construcción (branding espacial). A continuación, se realizará un análisis geográfico del territorio del Lluçanès para, posteriormente, dar a conocer los orígenes, la idiosincrasia y los objetivos descritos en el proyecto de desarrollo local Territoris serens. El detalle de la metodología utilizada (revisión de la literatura, análisis documental y grupo focal de discusión) precederá a la exposición de los resultados obtenidos. Finalmente, se presentará la discusión vinculada a las conclusiones, en relación directa con el análisis de los resultados, el marco teórico propuesto y los objetivos planteados.

\section{Metodología}

Esta investigación ha fundamentado su trabajo empírico en la implementación de metodologías de investigación cualitativas. La primera técnica de investigación utilizada se ha concretado en la revisión de la literatura vinculada directamente a los fundamentos teóricos del presente trabajo, esto es, marca y branding de territorios. De forma indirecta, el vaciado bibliográfico se refiere también a aspectos vinculados a la construcción social de sentido territorial, como por ejemplo identidad, paisaje o sentido de lugar. La obtención de un 
Cuadro 1. Ficha técnica del grupo focal de discusión Territoris serens

Metodología aplicada: grupos focales de discusión (GFdD).

Población implicada: agentes sociales, empresariales y ciudadanía con vinculación directa al proyecto Territoris serens.

Participantes: ocho miembros en total.

Fecha del trabajo de campo: miércoles, 21 de julio de 2010.

Lugar y duración: Consorci del Lluçanès (Santa Creu de Jutglar, Olost, Osona [Barcelona]). De 10.30 a 12.30 horas.

Estamentos y organizaciones representadas: Consorci del Lluçanès, Ajuntament de Lluçà, Ajuntament de Sant Boi de Lluçanès, Ajuntament d'Alpens, varios representantes del sector de la payesía, Instituto de Educación Secundaria de Prats de Lluçanès, Entidad Cultural SOLC.

Fuente: elaboración propia.

estado de la cuestión referido a las bases teóricas del artículo nos ha parecido un buen punto de partida para el afronte del estudio de caso Territoris serens (el Lluçanès). A continuación y complementariamente a la revisión de la literatura, se ha desplegado una etapa intermedia sobre la base de un análisis documental, entendido, en el contexto del presente artículo, como la recogida y el posterior vaciado del material escrito y/o visual más relevante vinculado específicamente al proyecto Territoris serens. De este modo, se ha procedido al análisis de soportes escritos y gráficos de cualquier naturaleza (dípticos, folletos, documentos de trabajo, páginas web, fotografías, etc.).

Finalmente, la metodología de investigación se ha completado con una etapa de contrastación de la información obtenida previamente en el ámbito teórico (revisión de la literatura y análisis documental). En este sentido, se ha considerado oportuno organizar un grupo focal de discusión vinculado al análisis cualitativo del proyecto Territoris serens. Esta técnica de investigación se ha desarrollado, por un lado, por su complementariedad con el proceso investigador previo (revisión de la literatura y análisis documental) y, por el otro, por la posibilidad que ofrece de someter a contrastación y/o validación los datos recopilados en fases anteriores de la investigación, mediante una introspección en la realidad vivida por múltiples agentes del territorio del Lluçanès directamente implicados con la marca territorial objeto de análisis. El grueso del aparato metodológico pretende dar cumplimiento al objetivo general del artículo que aquí nos ocupa: determinar el papel que la marca Territoris serens desempeña en el Lluçanès, en el marco más amplio de un proyecto de desarrollo rural y a ojos de la población directamente implicada en su implementación.

\section{El marco teórico}

\section{Marca $y$ «branding» territorial}

Los orígenes de la marca de territorio son difíciles de ubicar en el tiempo. Esto es así porque, en la delimitación temporal de las marcas de lugares, hay dos 
referentes principales. Por un lado, hay que considerar el ejercicio de branding (construcción de marca) encubierto que las naciones y los países han llevado a cabo históricamente de una forma implícita. En opinión de Anholt (2010), la vinculación entre marcas y territorios hay que situarla muchos años atrás, tal vez en la época de Alejandro Magno ( $356 \mathrm{aC}$ a $323 \mathrm{aC}$ ), quien fue de los primeros en entender que el éxito o el fracaso de los lugares dependía, en gran medida, de la imagen que proyectaban hacia el exterior. Los inicios documentados en la literatura referidos explícitamente al binomio formado por marca y territorio - en el que la marca tiene un papel realmente importante y no puramente testimonial, como ocurre en el ámbito de la promociónhay que situarlos a finales de la década de 1980 y principios de la de 1990, cuando autores como Bartels y Timmer publicaban, en 1987, la obra City Marketing: instruments and effects. Asimismo, otros autores como Ashworth y Voogd daban a conocer su trabajo titulado Selling the City en 1990 y, posteriormente, en 1993, aparecía uno de los títulos de referencia en la vinculación entre marcas, marketing y territorios que existe en la literatura académica, se trata de Marketing places: attracting investment, industry, and tourism to cities, states, and nations, a cargo de Philip Kotler, Donald H. Haider y Irving Rein (San Eugenio, 2011a).

En términos de evolución, el territorio y su comunicación han experimentado una transición que ha partido de unos niveles iniciales de promoción (comunicar por comunicar, sin una estrategia de largo plazo concreta detrás y con el objetivo único de vender), para evolucionar hacia niveles de venta de lugares (muy vinculados a la publicidad y a la comercialización de la ciudad en términos de cultura), para seguir hacia estrategias de marketing (que implica la adopción de buena parte de las lógicas empresariales en la gestión y comunicación de espacios), para así terminar el recorrido donde estamos ahora: en la era del branding de lugares, donde el énfasis se deposita en la marca y en su capacidad para diferenciar y posicionar a unos espacios determinados con el objetivo último de proyectar una imagen dirigida principalmente a un público externo, con el afán de captar no sólo turistas, sino también talento, inversión empresarial, infraestructura, etc. Para Ollé y Riu (2009), el branding se ocupa de crear una imagen que refuerce la reputación, fomente la fidelidad, garantice la calidad, transmita valor y ofrezca una idea de pertinencia con relación a una determinada marca. Del mismo modo, el proceso de branding se basa en el concepto de singularidad, en la creación, en la mente del consumidor, de una determinada percepción relacionada con la sensación de exclusividad de un producto y/o servicio determinado. Para Solsona (2008: 269), «El branding supone la capacidad de seducción, de comunicación a través de un símbolo o un lema de las bondades de un destino, de despertar los sentidos del potencial usuario, de motivarle para satisfacer sus necesidades sociales, afectivas, emocionales, es decir, la capacidad de generar y gestionar una marca».

En efecto, el branding, en el contexto del proyecto Territoris serens, pretende recuperar conceptos tradicionalmente asociados a la geografía y, más 
concretamente, a la geografía cultural ${ }^{1}$, tales como el paisaje ${ }^{2}$, la identidad ${ }^{3}$ y el sentido de lugar ${ }^{4}$, con el fin de colaborar en una estrategia de desarrollo rural ${ }^{5}$ adaptada al nuevo contexto de la Unión Europea y de la globalización. No se debe olvidar que el proceso de branding implica, per se, una construcción social de sentido territorial, en el caso que nos ocupa implementada a nivel local.

Los fundamentos del branding de lugares entroncan perfectamente con lo expresado por Fløysand y Jakobsen (2007), en cuanto a la progresiva comercialización de los espacios rurales mediante la proyección de un conjunto de narrativas, discursos o relatos que permitan posicionar a la ruralidad desde la creación de una imagen de marca muy vinculada al valor simbólico de sus paisajes (Soliva, 2007; San Eugenio, 2011b). Asimismo, Nogué y San Eugenio (2011: 19-20) han utilizado la expresión landscape branding para apelar al poder de evocación inducida del paisaje, para, posteriormente, transformar su mensaje a niveles de consumo simbólico y experiencial: «El proceso de landscape branding consiste, básicamente, en provocar la emergencia de un mensaje, de un relato asociado a un paisaje mediante el uso de técnicas variadas de marketing y comunicación, que utilizan un lenguaje persuasivo y emocional para llegar a sus públicos. En este sentido, representa una actual y manifiesta técnica de explotación del poder comunicativo del paisaje, trasladando determinados valores de identidad, personalidad y distinción hacia un proceso global de edificación de marca territorial».

1. Esta rama de la geografía dispensa un claro interés al lugar, a las identidades territoriales y a sus procesos de construcción social. Capellà y Lois (2002: 11-12) definen los objetivos de investigación propios de la geografía cultural: «A diferencia de otras ramas de la disciplina, las reflexiones de geografía cultural no definen un objeto de estudio en sí, sino que constituyen una verdadera óptica o mirada propia sobre el conjunto de las cosas, objetos y procesos sometidos a las lógicas espaciales y territoriales. [...] Cuando hablamos de geografía cultural debemos tal vez centrarnos más en una forma de pensamiento o en una mirada que vertimos sobre el espacio para darle un significado y un orden explicativo, una cosmogonía [...]».

2. El paisaje, ante las nuevas necesidades existenciales de «ser diferentes», parece desempeñar un rol decisivo a la hora de significar y representar las singularidades de los lugares y, por tanto, diferenciarlos ante la lógica homogeneizadora de la globalización (Roma, 2000; Nogué, 2005 y 2006).

3. La identidad, en un contexto de competitividad emergente entre territorios, es el elemento comercializador más importante en el proceso comunicativo de posicionamiento de espacios geográficos (Nogué, 1999 y 2007; Anholt, 2007).

4. El sentido de lugar tiende a determinar cómo la sociedad siente y piensa unas zonas determinadas. Se trata de una expresión habitualmente usada por los geógrafos cuando quieren enfatizar la importancia de los lugares como foco de sentimientos personales. Representa, en definitiva, el significado que la gente atribuye a espacios particulares. El sentido de lugar es el camino indicador de los significados y las sensaciones inherentes al espacio geográfico (Rose, 1995).

5. Saurí y Boada (2006: 316) ubican los antecedentes del desarrollo rural de los tiempos actuales: « [...] Las funciones estrictamente productivas (obtención de alimentos y de otros productos de la tierra), aunque, importantes, empiezan a dejar paso a funciones más vinculadas al consumo, especialmente el consumo de "naturaleza" o de "paisaje". Este es un cambio substancial que coincide, por otra parte, con un periodo de creciente marginalidad económica, política y social de las áreas rurales [...]». 
Curiosamente, la acepción "marca de territorio» ha sido poco usada en la literatura que relaciona marcas y espacios geográficos, tanto en lo referido al ámbito europeo como al anglosajón. Unicamente López-Lita y Benlloch (2005 y 2006) han utilizado abiertamente esta expresión para referirse a manifestaciones de marcas inscritas en localizaciones espaciales. De este modo, por "marca de territorio» hay que entender, según estos mismos autores, un dispositivo aglutinador de los elementos diferenciales de un espacio geográfico concebido para lograr un posicionamiento determinado. La situación originada por la emergencia de un mercado global de lugares, unido a una tendencia homogeneizadora, provoca que la necesidad de singularización sea más evidente que nunca. En este sentido, también consideran que la marca de territorio debe ocuparse de incrementar la competitividad de los lugares, así como de su atracción turística, favorecer unos niveles de inversión extranjera o conseguir un posicionamiento geoestratégico determinado, entre otros objetivos.

En lo referido a la presencia de marcas territoriales en espacios rurales, Cai (2002) afirma que, en las comunidades rurales, han proliferado el uso de marcas mancomunadas, de alcance supramunicipal, en clara alianza entre territorios rurales cercanos, en lo que el autor denomina como «branding cooperativo». Solsona (2008) sostiene que, a pesar de que el turismo rural ${ }^{6}$ es un producto que no basa su estrategia competitiva en las marcas (debido a que actualmente existen muy pocas en pleno desarrollo), en el futuro su presencia será decisiva en la lucha por atraer a la demanda. En concreto, afirma: «La marca se convertirá en el reflejo de la reputación, de lo que transmite el destino a sus usuarios» (p. 270).

\section{El territorio y el proyecto objeto de estudio}

\section{Análisis geográfico del Lluçanès}

En la lista de las cuarenta y una comarcas oficiales de Cataluña no aparece el Lluçanès, aunque ya en el siglo Xvir existió la subveguería del Lluçanès, plenamente integrada en la organización territorial del Principado vigente entre 1611 y 1716 (Collelldemont, 1994). Los límites de ese tiempo son muy similares a los que hoy identifican este territorio, que guarda una estructura territorial muy compacta de manera visible. El Lluçanès es, oficialmente, una agrupación de municipios que trabaja conjuntamente de manera coordinada y estable desde el año 2001 bajo el paraguas administrativo del Consorci del Lluçanès ${ }^{7}$. Asimismo, existe una reivindicación territorial en favor de la

6. Tal y como afirman Pulido y Cárdenas (2011), el desarrollo turístico en áreas rurales se ha producido de una forma espontánea, descontrolada, sin estrategia ni planificación alguna.

7. El Consorci per a la Promoció dels Municipis del Lluçanès es una entidad supramunicipal y supracomarcal que engloba los trece municipios considerados en el marco territorial del Lluçanès. La entidad tiene sus orígenes en el Organismo Autónomo Local «El Grau», creado 
petición de reconocimiento administrativo de la actual subcomarca ${ }^{8}$, tanto por parte de entidades y administraciones locales, como de sectores sociales e incluso particulares.

En efecto, el Lluçanès debe considerarse una unidad geográfica en forma de altiplano situada entre dos grandes ríos e integrada por una agrupación territorial de trece municipios ${ }^{9}$ adscritos a tres comarcas diferentes: Osona, el Berguedà y el Bages. Dispone de una distribución de múltiples núcleos de población caracterizados por una estrecha relación vecinal. La subcomarca que nos ocupa se localiza en la transición territorial de unión entre la llanura de Vic y el Berguedà, cercana a los Prepirineos, entre las comarcas del Ripollès, el Bages y el Berguedà. La dificultad de acceso a este espacio geográfico, debido a una disposición de redes de comunicación viaria de carácter tortuoso, ha mantenido este espacio alejado de los grandes procesos de industrialización y de crecimiento urbanístico vividos en los territorios vecinos (ubicados en los ejes de los ríos Ter y Llobregat).

Los productos de la tierra, la ruralidad y, en general, el sector primario siguen especialmente vivos en esta localización geográfica recóndita. La singularidad más acusada de esta subcomarca se explica por la gran diversidad y riqueza de su paisaje ${ }^{10}$, que abarca desde campos de cultivo hasta bosques de pinos y encinas, arroyos, riachuelos, cuevas y pozas, pasando por un amplio relieve. En total, el Lluçanès dispone de una extensión aproximada de 400 kilómetros cuadrados, donde residen poco más de 8.000 habitantes. El núcleo más poblado es Prats de Lluçanès, situado en el sector suroeste con 2.676 habitantes, seguido de Olost y Sant Bartomeu del Grau, con aproximadamente 1.000 habitantes cada uno de ellos. Por debajo, se sitúan Sant Feliu Sasserra, Oristà y Sant Boi de Lluçanès, donde viven entre 500 y 700 personas. Los siete municipios restantes acumulan menos de 500 habitantes, cuatro de los cuales no superan los 100 residentes ${ }^{11}$. Se observa, a partir de estos datos, un territorio

en 1999 con la finalidad de incentivar la formación, los servicios sociales o la inserción laboral, entre otros aspectos. En diciembre de 2001 acabó convirtiéndose en la actual figura de Consorci del Lluçanès. Fuente: Consorci del Lluçanès.

8. Por subcomarca hay que entender una agrupación territorial de municipios a los que les une algún rasgo diferencial, pese a no disponer de reconocimiento administrativo y/o territorial como comarca. Por tanto, la subcomarca se constituye a modo de agrupación territorial de segundo nivel por debajo de las comarcas.

9. Los municipios integrados en la agrupación territorial del Lluçanès son los siguientes: Alpens, Lluçà, Olost, Oristà, Perafita, Prats de Lluçanès, Sant Agustí de Lluçanès, Sant Bartomeu del Grau, Sant Boi de Lluçanès, Sant Feliu Sasserra, Sant Martí d’Albars, Santa Maria de Merlès y Sobremunt. En el contexto de esta investigación, entendemos por Lluçanès el espacio geográfico resultante de la unión de estos trece municipios, íntegramente gestionados por el Consorci del Lluçanès.

10. La excepcionalidad del paisaje existente en el Lluçanès se encuentra refrendado por lo descrito en el Catàleg de Paisatge de les Comarques Centrals, impulsado por el Observatori del Paisatge de Catalunya en 2008. Actualmente, el referenciado catálogo de paisaje se encuentra pendiente de publicación. Fuente: Observatori del Paisatge de Catalunya ( $h t t p: / /$ www.catpaisatge.netlesp/cataleg_terminis.php).

11. Todos los datos referidos a población se han obtenido de IDESCAT (Institut d'Estadística de Catalunya). Fuente: http://www.idescat.cat/. 


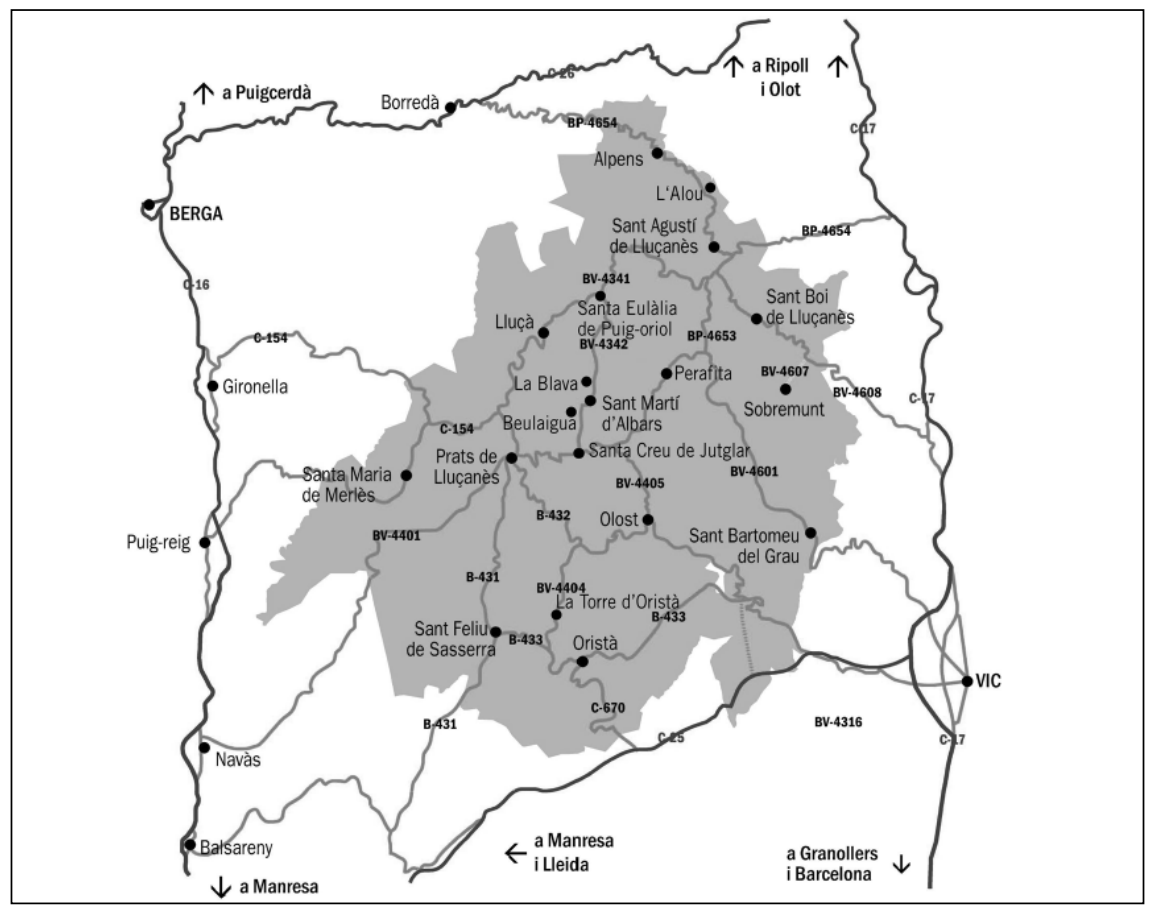

Figura 1. Mapa de los municipios adscritos a la agrupación territorial del Lluçanès. Fuente: Consorci del Lluçanès.

con núcleos de población relativamente pequeños, propios de una estructura territorial eminentemente rural, con una gran multitud de casas de payés y de actividad agraria, ganadera y silvícola por toda la subcomarca.

Veamos, a continuación, algunos datos demográficos y económicos referidos a la agrupación territorial del Lluçanès:

Cuadro 2. Recuentos de población en valores absolutos (Lluçanès)

\begin{tabular}{llllllllllll}
\hline 1996 & 2001 & 2002 & 2003 & 2004 & 2005 & 2006 & 2007 & 2008 & 2009 & 2010 & 2011 \\
\hline 8.431 & 8.326 & 8.271 & 8.263 & 8.188 & 8.109 & 8.145 & 8.059 & 8.125 & 8.145 & 8.145 & 8.011 \\
\hline
\end{tabular}

Fuente: padrón continuo del Instituto Nacional de Estadística (INE).

Cuadro 3. Recuentos de población ocupada por grandes sectores de actividad en las comarcas centrales de Cataluña en valores absolutos y porcentajes (Anoia, Bages, Berguedà, Osona y Solsonès).Fuente: Institut d'Estadística de Catalunya (IDESCAT)

\begin{tabular}{cccccc}
\hline Año & Agricultura & Industria & Construcción & Servicios & Total \\
\hline 2001 & $6.439 /(3,3 \%)$ & $69.543 /(35,9 \%)$ & $22.482 /(11,6 \%)$ & $95.253 /(49,2 \%)$ & 193.717 \\
1996 & $6.742 /(4,4 \%)$ & $66.242 /(42,9 \%)$ & $12.362 /(8,1 \%)$ & $68.812 /(44,6 \%)$ & 154.158 \\
1991 & $8.042 /(5,2 \%)$ & $73.381 /(47,6 \%)$ & $12.744 /(8,3 \%)$ & $59.997 /(38,9 \%)$ & 154.164 \\
\hline
\end{tabular}


Los datos muestran una disminución sostenida de población residente en el Lluçanès. En concreto, desde el año 1996 hasta 2011, este territorio ha experimentado la pérdida de 420 habitantes, lo que representa, en porcentaje, un $5,2 \%$ de la población total. En lo referido a la edad media de sus habitantes, se observa un aumento de los 42 años de media en el año 2000 a los 44,9 años de media en el año 2011, según se desprende de los datos obtenidos de la Diputación de Barcelona. Por tanto, podemos hablar de una tendencia progresiva al envejecimiento de la población. En lo relacionado con la actividad económica, se observa una notable presencia de la actividad industrial, seguida del sector de la construcción, aunque el sector dominante es el de los servicios, que experimenta un auge muy notable desde 1991 hasta 2001, puesto que aumenta su representación en la actividad económica de las comarcas centrales de Cataluña en un 37\%. Por tanto, podemos hablar de un claro proceso de tercerización de la actividad económica del territorio. Este dato se ve refrendado por las informaciones vinculadas al último trimestre de 2011 obtenidas del Observatori d'Osona per al Desenvolupament Local ${ }^{12}$, donde el peso de la contratación por sectores en el Lluçanès se produce en las siguientes condiciones: $60,24 \%$ relacionadas con el sector servicios, $23,70 \%$ vinculadas a industria, $12,85 \%$ asociadas a la construcción y, finalmente, el 3,21\% restante se relaciona con la agricultura.

\section{Descripción y análisis del proyecto "Territoris serens»}

Territoris serens deviene una propuesta de dinamización socioeconómica para un espacio rural concebida alrededor de un valor esencial construido socialmente para este espacio geográfico, esto es, la serenidad, a partir de la cual se define una estrategia de desarrollo local para el territorio del Lluçanès. El proyecto surge en 2005, cuando el Consorci del Lluçanès participa, con el Consell Comarcal de Osona, en la definición del Plan de Innovación Comarcal (Osona) ${ }^{13}$, que cuenta con la participación de las distintas oficinas de promoción económica de la comarca. De este estudio, surgen siete propuestas de innovación, una de ellas referida a nuestro objeto de trabajo: Territoris serens. En este sentido, se apostó por la puesta en marcha de un modelo singular de gestión territorial avalado por seis constataciones fundamentales (Consorci

12. Centro de estudios impulsado por el Consell Comarcal d'Osona ocupado en el análisis de los movimientos demográficos y de actividad económica de la comarca de Osona, así como de sus agrupaciones territoriales.

13. Se trata de un plan de innovación en el ámbito local para la comarca de Osona. Los antecedentes de este tipo de planificación y acción territorial se sitúan en el Consejo Europeo acontecido en Lisboa en el año 2000, cuando la Comisión Europea introduce una serie de reflexiones sobre el protagonismo creciente de las regiones en la definición y ejecución de las políticas de innovación, además de recomendar a los estados miembros una mayor coordinación con las políticas regionales de innovación (Terré, 2008). A partir de ahí, surge el primer Plan de Innovación de Cataluña 2001-2004, al que le sigue el Plan de Investigación e Innovación (2005-2008), en el cual se adscribe el Plan de Innovación de Osona (PIO). Actualmente se encuentra vigente el Plan de Investigación e Innovación (PRI) 2010-2013. 
del Lluçanès, 2009: 2): la amenaza de expansión territorial del entorno metropolitano; la incertidumbre sobre el futuro de la actividad económica y los puestos de trabajo del territorio; la percepción de desequilibrio en el acceso a los servicios fundamentales para el bienestar de la población en relación con los entornos más urbanos; la transformación, y en algunos casos pérdida, de los valores endógenos de los espacios rurales; la inquietud por conocer la experiencia de otras localidades que han formalizado una apuesta para afrontar los retos actuales desde un punto de vista alternativo, por ejemplo: con la anexión al movimiento slow y la necesidad de reflexionar sobre las cuestiones de innovación desde un ámbito rural, en el cual y a menudo este potencial está poco desarrollado.

El referente ideológico en cuanto a la construcción de una narrativa asociada al proyecto Territoris serens se sitúa en los preceptos desarrollados por el movimiento Cittaslow, que, a su vez, surge del movimiento Slow Food ('comida sin prisas'), aparecido en oposición frontal al fast food ('comida rápida'). La pausa, el sosiego y, en general, la huida de la inmediatez propia de entornos urbanos y/o metropolitanos representan los garantes y los valores fundamentales de los espacios rurales, de sus pueblos y de sus villas. Es a partir del interés del Lluçanès por el movimiento Cittaslow, así como de su preceptiva adecuación a un entorno rural, que surge el marco inspirador que acompaña a la iniciativa de desarrollo local Territoris serens, que supone un modelo de innovación para el Lluçanès, vehiculado a partir de los puntos de partida siguientes: la valorización de los productos locales tradicionales ${ }^{14}$, la forma de ocupación y uso del territorio y de sus recursos, así como las necesidades de sus residentes respecto a salud, formación, ocio o cultura, entre otras (Barniol, 2008).

En esta tesitura, Territoris serens es definido del siguiente modo: «Aquellos que apuestan por un modelo de desarrollo centrado en sus residentes, potenciando la participación y el dinamismo de los agentes así como de los recursos propios y haciendo de la serenidad un paradigma del estilo de vida que se persigue» (Consorci del Lluçanès, 2009: 4). Por tanto, un territorio sereno dispondrá de unas características y se convertirá en sede de la organización de un conjunto de procesos colectivos que posibiliten desarrollar, de forma individual y colectiva, y a partir de su capital territorial, un estilo de vida sereno (proclamado en la Jornada de Trabajo Territoris serens, Plan de Innovación de Osona, que tuvo lugar en el Castillo de Montesquiu (Osona), el 13 de mayo de 2008).

Los objetivos fundamentales de Territoris serens son los siguientes: $a$ ) promover la conservación del territorio y el paisaje como recurso endógeno; $b$ ) favorecer estilos de vida serenos, $\mathrm{y} c$ ) proponer una actividad económica basada en productos propios, de calidad y respetuosos con el medio ambiente (Con-

14. La nueva realidad económica de la ruralidad se concreta, a modo de ejemplo, en la revalorización de los productos regionales y del sector agroalimentario (vinculado a productos ecológicos y a denominaciones de origen calificadas) a modo de capital cultural (Mutersbaugh, 2005; Tregear, Arfini, Belletti y Marescotti, 2007). 


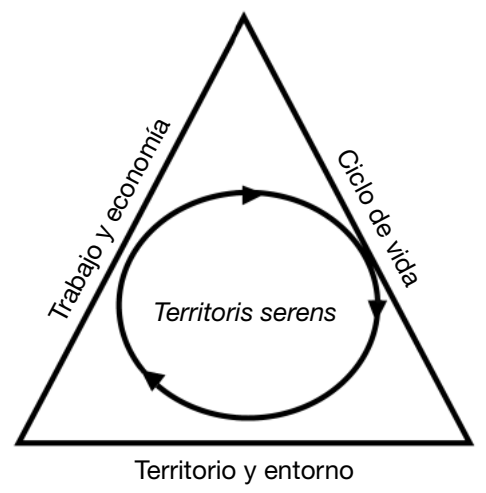

Figura 2. Ámbitos de actuación del proyecto de desarrollo local Territoris serens. Fuente: adaptado a partir de Territoris serens. Document de bases (Consorci del Lluçanès, 2009).

sorci del Lluçanès, 2009: 6). De esta forma, se pretende conseguir un modelo de territorio creado a partir de la definición de sus características (escenario), de unos procesos colectivos de toma de decisiones (directrices) y del establecimiento de un programa de actuaciones a corto y medio plazo (agenda política). A partir de aquí, surgen tres ámbitos prioritarios de actuación: territorio y entorno; ciclo de vida, y trabajo y economía.

\section{Territorio y entorno}

Esta línea de trabajo incide, con especial énfasis, en el principio de integridad paisajística, en la planificación y la gestión territorial. En concreto, esta división estratégica trabaja para garantizar futuros crecimientos urbanísticos orientados a partir de una articulación coherente y bien integrada. También se ocupa de asegurar un planeamiento urbanístico que permita valorizar el carácter especial de los espacios agrarios ${ }^{15}$. Asimismo, tiene asignada la misión de garantizar la protección de aquellos espacios naturales y rurales con una capacidad de evocación especial de valores asociados al bienestar y a la belleza. La última tarea asignada a este bloque temático se corresponde con la transformación, la preservación y la restauración de entornos y elementos patrimoniales en una oportunidad de empatía personal hacia el paisaje, de valorización de los espacios libres y singulares y de proyección de Territoris serens entre la población local y visitante.

15. Supone la puesta en valor del patrimonio natural (Soy, 2001; Valcárcel, 2004; Courtney, Hill y Roberts, 2006) capitalizado por el paisaje, que deviene un elemento fundamental de la imagen asociada al espacio rural, además de consolidarse a modo de valor de diferenciación esencial de su oferta turística (Pulido y Cárdenas: 2011: 168). 


\section{Ciclo de vida}

El segundo gran eje de actuación del proyecto incide en la vertiente social. Presta especial atención al fortalecimiento del capital social local, así como a la promoción de la autonomía personal como elementos clave del bienestar de la población. En este sentido, se concretan cuatro factores de incidencia prioritarios. En primer lugar, se impone la organización de la comunidad, de la sociedad civil, con el objetivo de afrontar el reto del desarrollo sereno desde una posición de unión de las comunidades locales. A continuación, aparece la estrategia "Territorios educadores», que se convierte en una iniciativa integrada de educación vinculada a la innovación con responsabilidad ante el entorno natural. En tercer lugar, se prioriza la conciliación a lo largo de la vida, con especial incidencia en las necesidades y en las oportunidades de la población en sus diferentes momentos vitales. Por último, el ámbito de trabajo "Ciclo de vida" prevé la creación de una red de servicios a la comunidad basada en el establecimiento de redes consorciadas de cooperación institucional, de servicios públicos, de equipamientos, de entidades y de cualquier otro recurso que sume esfuerzos para la mejora de la calidad de vida de sus residentes.

\section{Trabajo y economía}

Las tres divisiones de trabajo que se incluyen en la estrategia de desarrollo local Territoris serens tienen el objetivo de conseguir el máximo provecho del capital territorial sin dañarlo. En este contexto, las estrategias que se siguen en esta tercera línea de actuación se concretan en la promoción de unos productos agroalimentarios buenos, limpios y justos ${ }^{16}$, basados en la calidad de la producción local y el impulso de un turismo ${ }^{17} \mathrm{y}$ de unas actividades de ocio vinculadas al territorio y a su gente. En conjunto, se pretende la ejecución de tres principios rectores, a saber: la ruralidad, la calidad y la sostenibilidad de las instalaciones y las infraestructuras turísticas. Finalmente, este ámbito de actuación se refiere a la promoción de un tejido empresarial innovador y de alta calidad con propuesta de modelos de «empresa serena ${ }^{18}$ », esto es, empresas de pequeñas dimensiones.

\section{Resultados}

Los hallazgos del presente trabajo se mostrarán, fundamentalmente, a partir de los resultados obtenidos en el grupo focal. Ello se explica porque los datos

16. Resultado directo de las directrices que, para los productos alimenticios, establece el movimiento y la filosofía Slow Food (comida lenta).

17. El referido proceso de diversificación económica del espacio rural hacia el turismo no supone, según Brandth y Haugen (2011: 43) una profunda transformación identitaria de la ruralidad y del espíritu campesino, sino justamente lo contrario. Los autores sostienen que las identidades de los granjeros y sus narrativas asociadas resultan de un gran interés para el negocio del turismo.

18. Empresas adscritas al marco inspirador de Territoris serens, esto es, la serenidad y, por tanto, que mantengan un escrupuloso respeto sobre el entorno de ubicación. 
obtenidos en las etapas previas de la investigación, esto es, revisión de la literatura (marca y branding territorial) y análisis documental (Territoris serens), son sometidos a un proceso de comprobación y/o validación en el seno de la organización de una sesión grupal. Por tanto, entendemos que los resultados más relevantes vinculados a Territoris serens se obtienen del grupo de discusión $y$, en este sentido, reproducimos, a continuación, su contenido esencial.

La sesión grupal se inició en torno a la definición de las implicaciones de marca asociadas al proyecto de desarrollo local Territoris serens. En consecuencia, se preguntó si este proyecto nacía, en realidad, por la necesidad de poner en marcha una marca que dotara de identidad a la agrupación territorial del Lluçanès. La respuesta obtenida por parte del grupo fue en el sentido de concebir la propuesta de desarrollo local a modo de apuesta de reflexión sobre el modelo de desarrollo a seguir en los próximos años en este singular espacio geográfico. Sin embargo, sus miembros también hicieron notar la necesidad de posicionamiento e identificación del territorio, así como de proyección de sus valores singulares (estilo de vida sereno) y, por lo tanto, sí consideraron adecuada la posibilidad de desplegar un dispositivo de posicionamiento (marca). A partir de aquí, la conversación derivó hacia la definición del concepto «marca». Prácticamente todos los integrantes del grupo de discusión coincidieron en señalar que una marca era una manera sencilla de explicar un territorio y todo lo que contiene. De esta forma, los participantes entendían la marca a modo de elemento de simplificación de los atributos de un espacio, aunque uno de los miembros de la sesión grupal quiso matizar el significado que la mayoría del grupo atribuía a la marca, al considerarla como «todo lo que te ayuda a vender una idea». Otras opiniones prefirieron definirla como «un sello de calidad que nos diferencia».

Territoris serens ha permitido que se unieran espacios geográficos con características e inquietudes similares. El matiz de marca para Territoris serens es que ya ha permitido, de entrada, la unión de intereses compartidos, estableciendo alianzas a nivel supracomarcal (Osona, el Bages y el Berguedà). La vinculación de intereses con territorios de comarcas vecinas es clave para dotar de entidad un proyecto de estas características. Del mismo modo, el establecimiento de paralelismos y diferencias entre una marca comercial y una de territorio generó numerosas aportaciones entre los miembros del grupo, aunque hubo una opinión que reflejó, fielmente, el pensamiento mayoritario de todos los integrantes del colectivo, que, por su interés, reproducimos literalmente: «El problema se produce cuando un territorio se quiere vender como una marca comercial. Por principios, no debe ser nunca objetivo de un territorio convertirse en una marca-producto. Un territorio debe tener capacidad para ser lo suficientemente representativo como para que sus marcas puedan tener sentido por sí mismas. En esta línea, primero cabe definir cuál es la base del territorio y, en todo caso, las marcas que lo acompañan y singularizan deben surgir de una determinada realidad geográfica, la cual debe tener la suficiente capacidad para devolver al territorio lo que el territorio les ha ofrecido de base». 
Otros miembros del grupo destacaron la vocación de servicio público de la marca de territorio en detrimento de la marca comercial, excesivamente condicionada por las urgencias y por las lógicas de mercado (afán de lucro). Así, algunos integrantes de la sesión grupal consideraron que una marca de territorio bien posicionada podía generar beneficios para las comunidades locales, concretados, por ejemplo, en la mejora de los servicios básicos y en la llegada de servicios complementarios.

Lo que queda claro, y este es un extremo que aflora recurrentemente en el contexto de la sesión de grupo, es que Territoris serens supone la ejecución de una estrategia global de dinamización económica pensada para el territorio, un proyecto común, resultado de una reflexión previa y de una conciencia colectiva de definición de un intento de desarrollo local afín con la innovación y con el progreso para determinados territorios rurales.

En referencia a los orígenes más remotos de Territoris serens, los miembros del grupo ubican dicha iniciativa en el contexto de la actividad comarcal, del tejido asociativo, de la suma de actividades de los diferentes municipios, de los ayuntamientos, de la sociedad civil. En este momento (entre los años 2005 y 2006), se vio la necesidad de generar un proyecto transversal de identificación territorial (expresión literal surgida en el transcurso de la conversación). A partir de aquí, se busca un valor genuino y característico del territorio que permita generar una identidad de lugar firme para el Lluçanès. Fue en ese momento que se decidió que la serenidad era uno de los valores más preciados del Lluçanès y, bajo la inspiración del movimiento Slow ('lento'), que posteriormente dio lugar al concepto Cittaslow (combinación de un vocablo inglés y uno italiano que expresa la lentitud de las ciudades), se construyó un proyecto de desarrollo local y de identidad territorial que se integró en el Plan de Innovación de Osona (PIO). Dicho proyecto representa, según manifiesta el grupo, una extraordinaria oportunidad para unir innovación y ruralidad.

Muchos integrantes de la sesión de grupo destacaron la personalidad propia de los territorios rurales, a menudo autoacomplejados desde dentro y estereotipados desde fuera. En ese instante, surge, por parte de los participantes, la necesidad de reconocimiento administrativo del Lluçanès a modo de comarca a todos los efectos, a tenor de que su situación actual de comarca de facto dificulta el acceso a la financiación y a las subvenciones públicas. Asimismo, se afirma, en el transcurso de la sesión grupal, que la marca Territoris serens, ya en origen concebida como entidad supracomarcal (Osona, el Bages y el Berguedà), puede contribuir al reconocimiento oficial de la comarca del Lluçanès, ya que la marca es capaz de atomizar y aglutinar un conjunto de territorios con características, necesidades e inquietudes muy similares. Se entiende, también, que esta sería una de las principales funciones a desarrollar por la marca Territoris serens, ya que, en opinión del mismo grupo, visualiza la capacidad de movilización de un conjunto de espacios geográficos con intereses compartidos.

En el transcurso de la discusión, se afirma que la marca no debe servir sólo para aglutinar territorios, sino que también debe tener capacidad para valorizar los recursos territoriales (por ejemplo, el paisaje) del Lluçanès y, en general, de 
toda la oferta (turismo y productos de la tierra, entre otros elementos) de que dispone este espacio geográfico. De hecho, en la definición compartida de los valores y los atributos de la marca Territoris serens surgió el siguiente punto de vista, que, por su aportación al debate, reproducimos de nuevo literalmente: «No hay que inventar nada, lo que hay ya tiene suficiente valor. Lo único que falta es canalizarlo y comercializarlo adecuadamente, además de saber hacia dónde queremos ir. El Lluçanès es lo que es y no debe perder lo que es. No podemos poner una barrera en el mundo donde vivimos. Hay gente interesada en lo que aquí ofrecemos, por ejemplo, el turismo tranquilo que ofrece el Lluçanès es altamente valorado. Hay personas que buscan la tranquilidad, aunque no dispongan de todos los servicios y comodidades que estarían a su disposición en un entorno urbano y/o metropolitano». En este caso, se entiende que la marca debe cumplir con la función de visibilización y refuerzo de unos atributos de los cuales el territorio ya dispone per se.

Otro de los comentarios que generó un amplio acuerdo entre los integrantes del grupo fue la necesidad de entender la marca como un proceso que surge desde dentro y que trabaja, prioritariamente, en beneficio de la gente de la tierra, de la gente de casa. Este matiz es importante, ya que, según expresa el grupo, a menudo se percibe la marca como un dispositivo promocional desconectado de la realidad local, pensado, únicamente, para proyectar una determinada imagen de un territorio hacia el exterior. En este sentido, se afirma que Territoris serens surge de la voluntad de crear un territorio equilibrado, en consonancia con las necesidades de las comunidades locales, aunque también con espacio para las personas que deseen visitarlo. Sin embargo, el grupo sostiene que también se debe usar la marca para diferenciar y posicionar el territorio en el exterior, e insiste en la necesidad de no olvidar las repercusiones positivas que, para las comunidades autóctonas, puede llegar a tener el desarrollo de la marca que hoy nos ocupa. En opinión de los miembros del grupo, los valores que definen el territorio del Lluçanès, y que, por tanto, son trasladables a la marca, son la serenidad, la tranquilidad, la buena alimentación, el paisaje y, en definitiva, la posibilidad de acceder a un estilo de vida de calidad, donde el buen comer, el disfrute del paisaje y el vivir sosegadamente se convierten en sus principales activos.

A lo largo de la sesión, se mantiene que la marca Territoris serens puede hacer mucho por las comunidades locales, en el sentido de fortalecer el sentimiento de pertenencia y de orgullo de formar parte de un entorno privilegiado. Además del valor de la serenidad, se destaca también el rasgo diferencial aportado por el paisaje, ya que, además de su excepcionalidad, representa una vía de subsistencia (por ejemplo, gracias a la agricultura y a la ganadería). Se llega a la conclusión de que el paisaje es uno de los valores clave del territorio del Lluçanès. Al interrogar al grupo en torno al concepto de marca y de sus connotaciones de gestión y/o comunicación, todos acuerdan que Territoris serens debe implicar, en paralelo, gestión y comunicación. Gestión con el fin que la marca se integre de lleno en un proceso de desarrollo local, que es lo que acabará reportando los mayores beneficios, y también comunicación, porque 
existe la clara necesidad de fijar una identidad para el Lluçanès que permita su proyección, diferenciación y posicionamiento en los ámbitos interno y externo.

En consecuencia, el proyecto y la marca Territoris serens incluye dos aspectos fundamentales. En primer lugar, implica el diseño y la ejecución de un proyecto de desarrollo local para un espacio rural, el cual se puede gestionar con criterios de marca, esencialmente a partir de la fijación de una identidad y de la valorización de los activos del territorio. En segundo lugar, se impone un proceso de fijación y proyección de una marca para el Lluçanès, mediante la definición de una estrategia de comunicación a partir de la cual se pueda lanzar al exterior una determinada imagen diferenciada y en positivo. De alguna forma, la comunicación y la gestión de la marca en el contexto de Territoris serens se retroalimentan constantemente, ya que se pretende gestionar y al mismo tiempo comunicar el espacio rural del Lluçanès con criterios de marca. Finalmente, los integrantes de la sesión de discusión sostuvieron que, per se, el proceso de definición de la estrategia de futuro a seguir en el Lluçanès, de la cual surge la propuesta Territoris serens, ya ha valido la pena por sí misma, ya que ha supuesto la movilización de un buen número de personas provenientes de todos los ámbitos dispuestas a contribuir en la definición de un modelo de desarrollo económico e identitario de futuro para la subcomarca del Lluçanès.

\section{Discusión y conclusiones}

Una de las particularidades más reseñables en torno al proyecto Territoris serens viene determinada por su naturaleza no finalista. Ello supone que la llegada a la meta es importante, pero el recorrido realizado para llegar al final del circuito diseñado a partir de la estrategia seguida es tanto o más importante. En este sentido, el documento de bases del proyecto reza lo siguiente (Consorci del Lluçanès, 2009: 10): «El proceso no debe ser visto como algo que sólo vale la pena en la medida que es capaz de llevarnos a un lugar determinado y deseado. Nos interesa tanto o más el camino que vamos construyendo (los valores que se promueven, las formas de relación que se van consolidando, las formas de gestionar recursos que se vayan generando, la cultura de lo público y del territorio que se va afianzando...) quizá en detrimento de la consecución de determinados objetivos concretados rápidamente, por mucho que éstos sean coherentes con el escenario dibujado".

Por tanto, el mismo proceso ya implica la consecución de un hito. De hecho, las directrices que rigen todo el desarrollo de Territoris serens así lo constatan. Estas se refieren, por ejemplo, a la concreción de liderazgos de tipo social y político con capacidad para hacer triunfar a las iniciativas del proyecto. También se menciona la necesidad de actuar de acuerdo con una organización democrática, de participación activa y con un claro compromiso por parte de todos los actores implicados, todo ello en el marco de fondo de la conservación del territorio y de sus recursos naturales. Asimismo, la puesta en marcha de una estrategia educativa y de visión territorial en el nivel micro (pueblo a pueblo) forma parte de los principios y los valores del proyecto. 
En lo referente a la construcción de un discurso para el Lluçanès a partir de la proyección del valor «serenidad» mediante el uso de la marca Territoris serens, se constata la recuperación del "espíritu histórico de lucha comarcalista», en el sentido de que la reivindicación histórica de reconocimiento a nivel de comarca se mantiene vivo y se expresa, de forma actualizada, a través de la necesidad de definir una identidad contemporánea construida socialmente. Por tanto, la marca territorial ofrece una doble salida al espacio rural del Lluçanès. Por un lado, ejerce de elemento aglutinador de una reivindicación histórica referida a la disposición de una comarca propia y, por el otro, favorece la construcción de un relato asociado al campo, actualmente imprescindible en los procesos de comercialización de un espacio rural.

El paisaje, el sentido de lugar o la identidad son construcciones sociales preexistentes, ancladas en el territorio y producidas en una etapa histórica. Estas mismas construcciones han situado al Lluçanès en tierra de nadie, una terrae incognitae sumida en el peligro de sufrir un vacío ante las nuevas reglas impuestas por la etapa global que vivimos. Ante esta disyuntiva, Territoris serens implica una renovada propuesta de desarrollo implementada desde lo local mediante la ayuda inestimable del branding, que propone la construcción de una nueva imagen de la ruralidad propia del Lluçanès, en la cual el paisaje, el sentido de lugar y la identidad seguirán siendo importantes, aunque sometidos a un proceso de revalorización que posibilita un desarrollo económico de la región aprovechando el valor intangible asociado al atributo «serenidad», entre otros. Ello implica la transición de un estado en "vía muerta» resultado de la globalización y de la desindustrialización en determinados espacios rurales hacia la transformación de un activo (el branding territorial) con capacidad para generar riqueza en la nueva economía rural.

En el Lluçanès, se despliega, por tanto, una estrategia de formalización que incluye una doble vía (in situ e in visu) para dar forma a su paisaje (Roma, 2000). Por un lado, la formalización in situ tiene un carácter más normativo, de inventario o bien de gestión (por ejemplo: a través de los catálogos de paisaje, el urbanismo, etc.) relacionado con aspectos físicos y tangibles del paisaje. Por el otro, se produce una formalización in visu, que se ocupa específicamente de moldear la mirada de los visitantes y/o los potenciales visitantes del Lluçanès, mediante el ofrecimiento de una experiencia hedonista, de deleite con su paisaje (Urry, 2002).

En todo caso, debe subrayarse que, a estas alturas, Territoris serens representa una estrategia cuya definición no se ha detenido, sino que todavía se encuentra en proceso de redefinición, en gran parte debido a su excepcionalidad. Por todo lo expuesto, hoy la propuesta de desarrollo local de referencia presenta algunas incógnitas e inconcreciones, debido al contexto de incertidumbre económica en el cual nos encontramos sumidos. Sin embargo, el inicio del camino parece claro: vincular el espacio rural perteneciente al Lluçanès a uno de sus valores intangibles más representativos, esto es, la serenidad, mediante la creación de una marca - a estas alturas implícita - surgida desde dentro y con voluntad identitaria y de liderazgo de un proceso global de desarrollo local. 
Por tanto, podemos concluir que la implantación de la marca Territoris serens responde a la progresiva comercialización de los espacios rurales, especialmente necesitados de la ayuda de narrativas, discursos y/o relatos que permitan su posicionamiento en un nuevo mercado global de lugares. El argumento de la serenidad, vinculado al paisaje, a la identidad territorial y a un premeditado sentido de lugar, se ha construido y negociado, por tanto, de forma interesada, en el camino de situar al Lluçanès en la nueva economía de los servicios.

Las marcas de territorio se definen, ante todo, por la influencia que ejercen en la percepción de los individuos. En este sentido, la concreción de una identidad singular llevada a cabo mediante una marca ofrece reconocimiento y diferenciación a determinados espacios geográficos, lo cual favorece un posicionamiento ventajoso que, a su vez, se convierte en decisivo en cuanto a las preferencias de elección de los usuarios. Del mismo modo, la responsabilidad inicial de diseño, implantación y gestión de una marca de territorio es preferentemente de la Administración pública, aunque se manifiesta la necesidad de constituir partenariados con participación equitativa de representantes públicos y privados, así como de ciudadanos, que representa, en definitiva, una propuesta de gobernanza específica para la administración y la gestión de una marca de territorio, que, en el caso que nos ocupa, se produce en paralelo a la ejecución de una estrategia de desarrollo local.

Una marca de lugar implica, simultáneamente, gestión y comunicación. Gestión no sólo con implicaciones de marca (brand management), sino también a partir de una renovada intervención en el territorio basada en criterios de marca y, en último término, de marketing. Por tanto, la gestión se encuentra fuertemente arraigada al marketing, mientras que la comunicación de la marca de territorio se vincula al branding. Asimismo, las diferencias más representativas entre una marca de territorio y una marca comercial surgen, preferentemente, de las connotaciones de dinamización económica vinculadas a la implantación de marcas asociadas con espacios geográficos. Las implicaciones sociales (marca espacial), en contraposición a los intereses de mercado (marca comercial), son una constatación más de las divergencias conceptuales y de ejecución existentes entre estas dos tipologías de marca.

Todas las expresiones vinculadas a territorios y marcas parten de una cuestión esencialista: la asociación que se establece entre los lugares y la implementación de estrategias de comunicación que los sitúen en ventaja comparativa y competitiva, aunque, sorprendentemente, existe una importante falta de consenso en la definición del término "marca de territorio" desde un punto de vista holístico y transversal. En esta línea, una marca de territorio debe dar salida fehaciente a tres objetivos principales (por este orden): posicionamiento, sentimiento de pertenencia y adscripción por parte de las comunidades locales, $y$, finalmente, tiene que ejercer a modo de dispositivo generador de percepciones positivas del territorio objeto de representación.

La identidad es el elemento de singularidad de un territorio por excelencia. Del mismo modo, se constata que esa misma identidad no es hoy una cuestión menor. Actualmente, se trata de algo cercano a la supervivencia, no tanto por 
una cuestión mercantilista, sino a razón de una manifiesta y necesaria exaltación de la identidad local en tiempos de globalización. Esta reivindicación identitaria se puede canalizar, en parte, mediante un uso evolucionado del concepto tradicional de marca. Por tanto, hacer marca, o bien construir una marca (branding), no implica, en ningún caso, la tematización del territorio ${ }^{19}$, sino que supone una indagación y una puesta en valor posterior de sus raíces identitarias. En este sentido, la marca Territoris serens nos parece un buen ejemplo de ello.

La marca de territorio se constituye, al mismo tiempo, en una expresión retórica y en un dispositivo de inserción hacia una vorágine competitiva entre espacios geográficos para la captación de recursos de naturaleza variada. Por tanto, el proyecto Territoris serens, entendido a modo de marca de lugar, debe considerarse un elemento de gestión territorial, a tenor de su meridiana implicación en lo referido a la concreción de una identidad territorial a partir de la cual se puede implementar un proceso de desarrollo local. A lo largo del presente trabajo, también se ha podido constatar que el proceso de desarrollo local que nos ocupa se vincula irrenunciablemente a elementos identitarios que, en muchos casos, resultan intangibles (la serenidad, el sosiego). Estos elementos acaban concretándose en la definición de una marca de territorio, ya sea implícita o explícita, que implica una etapa de redefinición y fijación de identidades actualmente imprescindible. Esta definición comunitaria del "¿Quiénes somos?» se integra en un proceso global de desarrollo local. En este sentido, el «Hacia dónde queremos ir?» que implica el diseño de una estrategia de dinamización económica y/o desarrollo local parte de un previo «¿Quiénes somos?» que obliga a las comunidades locales a llevar a cabo un ejercicio de fijación y/o atomización identitaria a partir de la cual iniciar un proceso de desarrollo territorial.

Del mismo modo, las marcas de territorio que surgen desde dentro, por deseo o necesidad de las comunidades locales autóctonas, ponen en valor el sentimiento y el orgullo de pertenencia a un emplazamiento geográfico determinado. Asimismo, el proceso que conlleva su definición posibilita, en algunos casos, el inicio de procesos de dinamización económica forjados en consonancia con el valor identitario del paisaje y de los productos agroalimentarios que proporciona.

Finalmente, cabe reseñar que, ante el molde homogeneizador propio de la globalización, los territorios agrarios y rurales se atomizan, usan su identidad diferencial, se interesan por lograr una marca (en muchas ocasiones, no explícita, no consciente) que les garantice la continuidad y la pervivencia de su tradición identitaria. La supervivencia, en tiempos de globalización, sobre todo en lo referido a espacios agrarios y rurales, pasa por el mantenimiento de su identidad. En efecto, las marcas territoriales ejercen una influencia crecien-

19. Donaire (2012) define «tematización» como la transformación de un territorio en un tema, en un simulacro o bien en un pastiche explícito, manifiesto. El paradigma de la tematización del territorio resulta ser un parque temático. 
te en el contexto de una necesidad progresiva, por parte de los territorios, de diferenciarse en relación con un entorno espacial aparentemente homogéneo. Por decirlo de algún modo, asistimos a un proceso completo de comercialización del espacio geográfico, donde las estrategias de marketing, branding y comunicación desarrollan un papel preponderante. En este sentido, resulta muy interesante adentrarse en el estudio de los procesos de diseño, implantación y gestión de marcas de territorio, sobre todo para llegar a determinar posibles lógicas de actuación del proceso de marca en un contexto espacial, así como para establecer paralelismos con las lógicas de implantación y gestión propias del ámbito corporativo. De la experiencia de análisis reciente entre la naturaleza de una marca comercial y una marca de territorio, se extrae una práctica equiparación en cuanto a su diseño, implantación y gestión posterior, aunque las connotaciones de implicación social y de dinamización económica que le son atribuibles la alejan de los simples intereses de mercado propios de las marcas corporativas.

\section{Agradecimientos}

Los autores desean expresar su agradecimiento al equipo evaluador del presente trabajo por sus valiosos comentarios y sugerencias a la primera versión del manuscrito. De igual manera, también quieren mostrar su gratitud al Dr. Joan Nogué, al Dr. Francesc Roma y al Dr. Xavier Ginesta por sus inestimables aportaciones y por su decisiva contribución a la mejora del artículo de referencia.

\section{Referencias bibliográficas}

Anholt, S. (2007). Competitive identity: The new brand management for nations, cities and regions. Basingstoke: Palgrave Macmillan.

- (2010). Places: Identity, image and reputation. Hampshire: Palgrave Macmillan.

Barniol, M. (2008). També es poden fer les coses d'una altra manera [en línea]. Santa Creu del Jutglar: Consorci del Lluçanès, 2008. <http://www.territoriserens.cat/ assets/plugindata/poola/05NotadePremsaMontseBarniol.pdf> [Consulta: 5 agosto 2011].

Brandth, B. y Haugen, M.S. (2011). «Farm diversification into tourism: Implications for social identity?». Journal of Rural Studies, 27 (1), 35-44.

CAI, L.A. (2002). "Cooperative branding for rural destinations». Annals of Tourism Research, 29 (3), 720-742.

Capellà, H. y Lois, C. (2002). «Geografía cultural: la gran desconocida». Boletín de la Asociación de Geógrafos Españoles, 34, 11-18.

Collelldemont, P. (1994). El Lluçanès. Girona: Edicions Periòdiques de les Comarques.

Consell Comarcal D'Osona (2011). El Lluçanès (informe trimestral de la dinàmica del mercat laboral, últim trimestre de 2011). Vic: Observatori d'Osona per al Desenvolupament Local.

ConsorCi Del LluÇANÈs (2009). Territoris serens: Document de bases [en línea]. Santa Creu del Jutglar, Barcelona. <http://www.territoriserens.cat/assets/plugindata/ poola/TerritorisSerens.\%20Bases.pdf> [Consulta: 21 agosto 2011] 
Courtney, P.; Hill, G. y Roberts, D. (2006). «The role of natural heritage in rural development: An analysis of economic linkages in Scotland». Journal of Rural Studies, 22 (4), 469-484.

Diputació de Barcelona (2006). Pla d'Innovació d'Osona [en línea]. Barcelona: Àrea de Promoció Econòmica. <http://www.diba.cat/documents/175591/762087/promoeco-plans-descarregues-pio_estat_projectes-pdf.pdf> [Consulta: 26 agosto 2011].

Donaire, J.A. (2012). Turismo cultural: Entre la experiencia y el ritual. Bellcaire d'Empordà: Vitel.la.

Fløysand, A. y JaKobSEn, S.E. (2007). "Commodification of rural places: A narrative of social fields, rural development, and football». Journal of Rural Studies, 23 (2), 206-221.

López-Lita, R. y Benlloch, M.T. (2005). «De la marca comercial a la marca territorio". Recerca: Revista de pensament $i$ anàlisi, 5, 87-100.

- (2006). «¿Necesitamos marcas territorio?». Técnica económica, 175, 50-52.

Mutersbaugh, T. (2005). «Just-in-space: Certified rural products, labor of quality, and regulatory spaces». Journal of Rural Studies, 21 (4), 389-402.

Nogué, J. (1999). «El retorno al lugar: La creación de identidades territoriales». Claves de Razón Práctica, 92, 9-11.

- (2005). "Paisatge i identitat territorial en un context de globalització». Treballs de la Societat Catalana de Geografia, 60, 173-183.

- (2006). «La producción social y cultural del paisaje». En: Mata, R. y TArroja, A. (coord.). El paisaje y la gestión del territorio: Criterios paisajisticos en la ordenación del territorio y el urbanismo. Barcelona: Diputació de Barcelona, 135-142.

- (2007). «Territorios sin discurso, paisajes sin imaginario: Retos y dilemas». Ería, 73-74, 373-382.

Nogué, J. y SAn Eugenio, J. (2011). "The communicative dimension of landscape: A theoretical and applied proposal». Revista de Geografía Norte Grande, 49, 7-24.

Ollé, R. y Riu, D. (2009). El nuevo brand management: Cómo plantar marcas para hacer crecer negocios. Barcelona: Gestión 2000.

Pulido, J.I. y CÁrdenas, P.J. (2011). «El turismo rural en España: Orientaciones estratégicas para una tipología aún en desarrollo». Boletín de la Asociación de Geógrafos Españoles, 56, 155-176.

Roma, F. (2000). La construcció medial de la muntanya a Catalunya (segles XV-XX): una mirada al paisatge des de la geografía cultural. Tesis doctoral. Cerdanyola del Vallès: Universitat Autònoma de Barcelona.

Rose, G. (1995). «Place and identity: A sense of place». En Massey, D. y Jess, P. (eds.). A place in the world Oxford: The Open University, 87-132.

SAN Eugenio, J. (2011a). La transformació de territoris en marques: el reconeixement i la diferenciació d'identitats espacials en temps postmoderns: Un estat de la qüestió. Tesis doctoral. Barcelona: Universitat Pompeu Fabra.

- (2011b). Teoria i mètodes per a marques de territori. Barcelona: UOC.

SAurí, D. y BoAda, M. (2006). "Sostenibilidad y cultura campesina: hacia modelos alternativos de desarrollo rural: Una propuesta desde Cataluña». Boletín de la Asociación de Geógrafos Españoles, 41, 315-328.

Soliva, R. (2007). «Landscape stories: using ideal type narratives as a heuristic device in rural studies». Journal of Rural Studies, 23 (1), 62-74.

Solsona, J. (2008). «Las marcas-destino de turismo rural en España». En Pulıdo, J.I. (coord.). El turismo rural: Estructura económica y configuración territorial en España. Madrid: Síntesis, 261-286. 
Soy, A. (2001). Economia politica i sobiranisme. Barcelona: Mediterrània.

Terré, E. (2008). Guia per elaborar plans d'innovació en l'àmbit local. Barcelona: Generalitat de Catalunya.

Tregear, A.; Arfini, F.; Belletti, G. y Marescotti, A. (2007). «Regional foods and rural development: The role of product qualification». Journal of Rural Studies, $23(1), 12-22$.

URRY, J. (2002). The Tourist gaze. Londres: Sage.

VALCÁRCEL, J. (2004). «Áreas de montaña: de la supervivencia a la integración». Boletín de la Asociación de Geógrafos Españoles, 38, 5-28. 